\title{
Kesahihan Isi Tindak Tutur Konstatif Berbahasa Indonesia
}

\author{
Mohammad Fakhrudin, Sukirno, dan Bagiya \\ Universitas Muhammadiyah Purworejo \\ m_fakhrudin55@yahoo.co.id
}

\begin{abstract}
Abstrak
Penelitian ini bertujuan mendeskripsikan penggunaan tindak tutur konstatif berbahasa Indonesia dan cara menguji kesahihan isinya. Data yang berupa tuturan bersumber pada media cetak dan media elektronik. Data tersebut disediakan dengan teknik baca-catat, rekam-catat, dan pembangkitan kembali secara kreatif oleh peneliti. Analisis data dilakukan dengan metode padan, sedangkan hasil analisis data disajikan dengan teknik informal. Dalam penelitian ini disimpulkan bahwa (1) tindak tutur konstatif berbahasa Indonesia dapat ditemukan dalam kehidupan sehari-hari, terutama dalam wacana ilmiah, (2) agar dapat memastikan kesahihan isi tuturan, petutur harus mengujinya, (3) pengujian dapat dilakukan dengan mengajukan pertanyaan tentang "dunia" isi tuturan, dan (4) berdasarkan kesahihan isinya, ada dua macam tindak tutur konstatif berbahasa Indonesia, yakni (a) tidak tutur konstatif yang sahih dan (b) tidak tutur konstatif yang tidak sahih.
\end{abstract}

Kata kunci: kesahihan isi, tindak tutur konstatif, dunia isi tuturan

\section{PENDAHULUAN}

Pada akhir-akhir ini, cukup banyak orang yang tertipu karena tidak menguji kesahihan isi tuturan sebelum bertindak. Misalnya, ketika membaca surat, sms, atau menerima telepon dari seseorang, atau "suatu perusahaan” mereka langsung percaya akan kesahihan isi tuturan itu. Mereka mengikuti apa pun yang diminta. Jika diminta mengirimkan uang ke nomor rekening yang disebut dalam surat, mereka pun mengirimkannya. Biasanya hal ini terjadi karena di dalam surat itu disebutkan bahwa petutur terpilih sebagai penerima hadiah yang sangat besar. Namun, mungkin juga ada tuturan yang berisi berita kecelakaan yang menimpa keluarganya. Dalam berita itu dikatakan bahwa anak, suami, atau istri penerima telepon mengalami kecelakaan dan akan dioperasi di rumah sakit. Pengirim berita mengatakan bahwa dia petugas rumah sakit atau polisi yang menangani kecelakaan itu. Untuk keperluan operasi, keluarga korban diminta agar segera mentransfer uang ke nomor rekening tertentu. Setelah mentransfer uang, "keluarga korban" baru melakukan konfirmasi. Ternyata berita itu tidak benar.

Korban penipuan tidak hanya orang yang berpendidikan dan berstatus sosial rendah, tetapi juga berpendidikan dan berstatus sosial (cukup) tinggi. Oleh karena itu, masalah kesahihan isi tuturan perlu mendapat perhatian.

Dalam kehidupan sehari-hari, terdapat tuturan yang difungsikan untuk menyatakan sesuatu. Menurut Austin (1962), tindak tutur yang demikian disebut tindak tutur konstatif. Isi tuturan ini mengandung nilai benar dan salah (Wijana, 1996: 24), yang berarti dapat diuji sahih tidaknya. Sesuai dengan fungsinya, tindak tutur konstatif dapat ditemukan dalam kehidupan sehari-hari. Pada wacana ilmiah, tuturan yang demikianlah yang digunakan karena mengutamakan informasi. Tuturan di bawah ini merupakan contoh tuturan konstatif.

(1) Universitas Muhammadiyah Purworejo beralamatkan di Jalan K.H.A. Dahlan 3 dan 6 Purworejo

Disebut tuturan konstatif karena isi tuturan itu dapat diuji sahih tidaknya. Pengujian dilakukan dengan mengajukan pertanyaan tentang “dunia” yang berhubungan dengan isi tuturan tersebut 
(Rustono,1999: 33). Tuturan Universitas Muhammadiyah Purworejo dapat diuji dengan mengajukan pertanyaan benarkah ada perguruan tinggi yang bernama Universitas Muhammadiyah Purworejo. Jawaban pertanyaan itu dapat dicari dalam Direktori Perguruan Tinggi. Jika ditemukan, berarti isi tuturan itu sahih. Tuturan beralamatkan di Jalan K.H.A. Dahlan 3 dan 6 Purworejo dapat diuji dengan pertanyaan yang berhubungan dengan "dunia” geografi. Dengan cara ini diketahui bahwa Purworejo merupakan kabupaten di Jawa Tengah. Selanjutnya, nama jalan itu diuji dengan membaca peta Kabupaten Purworejo dan memang ada. Jadi, Universitas Muhammadiyah Purworejo beralamatkan di Jalan K.H.A. Dahlan 3 dan 6 Purworejo merupakan tuturan yang sahih isinya.

\section{METODE PENELITIAN}

Penyediaan data dilakukan dengan teknik baca-catat, rekam-catat, dan pembangkitan kembali secara kreatif oleh peneliti. Instrumen pengumpulan data penelitian ini adalah peneliti sendiri, dilengkapi dengan perekam dan form pencatat data. Form pencatat data itu disimpan dalam hard disk. Analisis data dilakukan dengan metode padan (Djajasudarma, 1993: 58), sedangkan hasil analisis data disajikan dengan teknik informal (Sudaryanto, 1993: 145-146).

\section{TEMUAN DAN PEMBAHASAN}

Dalam bagian ini disajikan temuan dan pembahasannya. Data yang disajikan dikelompokkan menjadi dua, yakni (1) tuturan ilmiah dan (2) tuturan nonilmiah.

\section{Tuturan Ilmiah}

1. Memasuki milenium ketiga, dunia memasuki era ekonomi global berbasis pengetahuan. Pada era ini pertumbuhan ekonomi, kemakmuran, dan kesejahteraan suatu bangsa amat dipengaruhi oleh kemampuan bangsa tersebut dalam menguasai ilmu pengetahuan dan teknologi (Priyo Darminto, 2008).

2. Pengalaman selama ini menunjukkan bahwa pengajaran bahasa khususnya pengajaran ilmu bahasa dengan data-data yang abstrak yang terlucut dari konteks pemakaiannya telah gagal membuktikan kehandalannya sebagai bahan ajar yang mampu menjadikan bahasa dan penggunaannya sebagai suatu aktivitas manusia yang penting dan menarik untuk dipelajari. (Wijana, 2003)

3. Berdasarkan hasil analisis data dapat disimpulkan bahwa (a) evaluasi program pembelajaran IPS model EKOP dinilai sebagai salah satu model evaluasi yang baik. [....] (Eko Putro Widoyoko, 2007)

Ketiga tuturan tersebut merupakan sampel tuturan wacana ilmiah. Tuturan (1) dan (3) diambil dari abstrak disertasi, sedangkan tuturan (2) merupakan pidato pengukuhan. Semuanya telah diuji kesahihannya secara akademis. Dengan demikian, isi tuturan itu sahih secara akademis. Tuturan yang demikian sesuai dengan ciri-ciri bahasa untuk karangan ilmiah sebagaimana dikemukakan oleh Moeliono (1981: 65), yakni, antara lain, menggunakan bentuk kalimat yang mirip dengan proposisi logika dan menggunakan bahasa yang mengutamakan informasi, bukan imajinasi. 


\section{Tuturan Nonilmiah}

Ada tiga sampel data yang disajikan, yakni (a) surat yang berkop Badan Akreditasi Nasional Perguruan Tinggi, (b) percakapan rektor melalui telepon, dan (c) tuturan yang berhubungan dengan kasus Dimas Kanjeng Taat Pribadi (DKTP). Di bawah ini disajikan ketiga data tersebut dan pembahasannya.

1. Badan Akreditasi Nasional Perguruan Tinggi (28 Maret 2011)

Pada surat yang berkop Badan Akreditasi Nasional Perguruan Tinggi ada dua kelompok tuturan yang diuji kesahihan isinya, yaitu nomenklatur dan alamat.

a. Nomenklatur

Beberapa nomenklatur yang ditemukan adalah (a) Badan Akreditasi Nasional Perguruan Tinggi, (b) BAN-PT Mendiknas RI, (c) Ditjen Mendikdasmen Mendiknas RI, (d) Komisi X RI, dan (e) Ketua BAN-PT RI.

Untuk menguji sahih tidaknya isi tuturan (a) s.d. (e), diajukan pertanyaan tentang "dunia” yang berhubungan dengan nomenklatur tersebut. Nomenklatur (a) sahih karena ada lembaga yang bernama Badan Akreditasi Nasional Perguruan Tinggi. Lembaga tersebut dibentuk berdasarkan Peraturan Menteri Pendidikan Nasional Republik Indonesia Nomor 28 Tahun 2005 tentang Badan Akreditasi Nasional Perguruan Tinggi.

Nomenklatur (b) tidak sahih karena pada Peraturan Menteri Pendidikan Nasional Republik Indonesia Nomor 28 Tahun 2005 tentang Badan Akreditasi Nasional Perguruan Tinggi, Pasal 2, ayat (2) dinyatakan "BAN-PT merupakan badan nonstruktural yang bersifat nirlaba dan mandiri yang bertanggung jawab kepada Menteri.” Dengan demikian, BAN-PT bukan organ bagian Mendiknas RI.

Nomenklatur (c) Ditjen Mendikdasmen Mendiknas RI tidak sahih. Yang sahih adalah Mandikdasmen, yakni akronim Manajemen Pendidikan Dasar dan Menengah. Jika akronim itu diikuti Mendiknas RI sehingga menjadi frasa Ditjen Mendikdasmen Mendiknas RI, frasa itu tidak sahih. Pada alamat BAN-PT, frasa yang sahih adalah Kementerian Pendidikan Nasional RI. Dengan demikian, nomenklatur yang sahih lengkapnya adalah Ditjen Mandikdasmen Kementerian Pendidikan Nasional RI.

Nomenklatur (d) tidak sahih. Ketidaksahihannya disebabkan oleh ketidaklengkapan nomenklatur. Jika yang dimaksudkan adalah komisi yang ada di DPR RI 2009-2014, nomenklatur yang sahih adalah Komisi X DPR RI. Komisi ini membidangi tugas, antara lain, pendidikan.

Nomenklatur (e) tidak sahih. Ketidaksahihannya disebabkan oleh kelebihan singkatan RI di sebelah kanan Ketua BAN-PT. Nomenklatur yang sahih adalah Ketua BAN-PT tanpa RI.

b. Alamat

Kompelek Ditjen Mendikdasmen Mendiknas RI G.D. Lt. II

Jln. Fatmawati - Cipete - Jakarta Selatan12410, Telp: (021) 30266398, Fax: (021) 3902159.

Isi tuturan alamat tersebut tidak sahih. Pada tahun 2011, alamat BAN-PT selengkapnya adalah sebagai berikut. 
Komplek Ditjen Mandikdasmen Kementerian Pendidikan Nasional RI Gedung D Lantai 1 Jl. RS. Fatmawati Cipete - Jakarta Selatan 12410 Telepon: (+62-21) 7668690, 75915521, 7694403 Email: sekretariat.banpt@gmail.com Website:http://banpt.depdiknas.go.id

2. Percakapan rektor melalui telepon

Dalam percakapan berikut, penelepon mengaku sekretaris dirjen dikti.

Konteks: Rektor menerima telepon di ruang kerjanya dari seseorang yang belum dikenal dan menginisiasi percakapan. Percakapan dilakukannya dengan telepon kantor.

(1) transkrip percakapan

01. REKTOR : "Assalamu 'alaikum."

02. PENELEPON : "Salam. Apakah betul saya bicara dengan Pak R?"

03. REKTOR : "Betul."

04. PENELEPON : "Begini, Pak Rektor. Saya sekretaris dirjen dikti. Bagaimana akreditasi UMP?"

05. REKTOR : "Maksud Bapak?"

06. PENELEPON : "Apakah sudah terakreditasi semua?"

07. REKTOR : "Yah, ada yang sudah. Ada yang belum."

08. PENELEPON : "Nah, nanti sore saya akan rapat dengan bapak dirjen."

09. REKTOR : "Em ... lalu?"

10. PENELEPON : "Yah ... apakah perlu kita usahakan? Nanti saya sampaikan. Kalau ya, saya

11. REKTOR : "Em ... begini, Pak. Biasanya akreditasi itu kami urus melalui BAN-PT.

Ada surat resmi dari BAN-PT."

12. PENELEPON : "Ya, ya." (Percakapan diputus/ditutup oleh penelepon)

Isi tuturan yang diuji kesahihannya adalah sekretaris dirjen dikti dan akreditasi. Dirjen dikti (apalagi sekretarisnya) tidak mempunyai tugas pokok dan fungsi membantu proses akreditasi perguruan tinggi. Proses akreditasi telah diatur dalam Peraturan Menteri Pendidikan Nasional Nomor 28 Tahun 2005. Lebih-lebih lagi, sekretaris dirjen dikti mengisiniasi komunikasi melalui telepon. Dengan demikian, isi tuturan penelepon (04) dan (10) tidak sahih.

3. Tuturan yang berhubungan dengan kasus DKTP

(2) Ustad Dimas Kanjeng .... (Publikasi Dimas Kanjeng, 12 Agustus 2015)

Tuturan (5) digunakan oleh sebagian pengikut DKTP. Isi tuturan (5) tidak sahih. DKTP tidak fasih membaca Alquran dan tidak menguasai kitab-kitab yang ditulis oleh ulama terkenal. Jadi, sebutan Ustad tidak sahih. (Periksa Compas.com. news, 29-09-2016)

(3) Yang Mulia .... (TransTv Surabaya, CNN Indonesia, 29 September 2016)

"Kami sama sekali nggak yakin. Wong nyamuk saja Yang Mulia nggak membunuh. Lalat, nggak mau mbunuh, Yang Mulia. Apalagi manusia [...]."

Sapaan Yang Mulia dalam bahasa Indonesia digunakan untuk menyapa raja atau menyapa tamu negara misalnya presiden, raja, perdana menteri atau duta besar. Berdasarkan 
penggunaan sapaan itu oleh pengikutnya, berarti DKTP sangat dihormati oleh pengikutnya dan DKTP dinyatakan sebagai raja. Namun, setelah diuji, isi tuturan itu tidak sahih karena dia adalah anak orang biasa dan tidak mempunyai wilayah kekuasaan sebagaimana layaknya raja.

\section{KESIMPULAN}

Penelitian ini disimpulkan bahwa (1) tindak tutur konstatif berbahasa Indonesia dapat ditemukan dalam kehidupan sehari-hari, terutama dalam wacana ilmiah. Kesahihan isi tuturan dalam wacana ilmiah bersifat sangat mengikat karena wacana ilmiah harus berisi kebenaran yang dapat dipertanggungjawabkan secara ilmiah. (2) Agar dapat memastikan kesahihan isi tuturan, petutur harus mengujinya. Pengujian sangat diperlukan agar petutur tidak tertipu. (3) Pengujian dapat dilakukan dengan mengajukan pertanyaan tentang "dunia" isi tuturan. (4) Berdasarkan kesahihan isinya, ada dua macam tindak tutur konstatif berbahasa Indonesia, yakni (a) tidak tutur konstatif yang sahih dan (b) tidak tutur konstatif yang tidak sahih.

\section{DAFTAR PUSTAKA}

Austin, J.L. 1962. How to Do Things with Words. Oxford New York: Oxford University Press.

Djajasudarma, Fatimah. 1993. Metode Linguistik. Bandung: PT Eresco.

Moeliono, Anton M. 1981. Pengembangan dan Pembinaan Bahasa. Jakarta: Djambatan.

Peraturan Menteri Pendidikan Nasional Republik Indonesia Nomor 28 Tahun 2005 tentang Badan Akreditasi Nasional Perguruan Tinggi.

Priyo Darminto, Bambang. 2008. "Studi Perbandingan Model-Model Pembelajaran Berbasis Komputer dalam Peningkatan Kemampuan Berpikir Matematis Tingkat Tinggi Calon Guru di Perguruan Tinggi Muhammadiyah”. Disertasi UPI Bandung.

Rustono. 1998. Pokok-Pokok Pragmatik. Semarang: IKIP Semarang Press.

Sudaryanto. 1993. Metode dan Aneka Teknik Analisis Bahasa. Yogyakarta: Duta Wacana University Press.

Widoyoko, Sugeng Eko Putro. 2007. "Pengembangan Model Evaluasi Program Pembelajaran Ilmu Pengetahuan Sosial di SMP.” Disertasi Universitas Negeri Yogyakarta.

Wijana, I Dewa Putu. 1996. Dasar-Dasar Pragmatik. Yogyakarta: ANDI.

Wijana, I Dewa Putu. 2003. "Wacana Dagadu, Permainan Bahasa, dan Ilmu Bahasa.” Pidato Pengukuhan Guru Besar UGM Yogyakarta. 